\title{
Molecular evidence for long-distance colonization in an Indo-Pacific seahorse lineage
}

\author{
Peter R. Teske ${ }^{1,9, *}$, Healy Hamilton ${ }^{2,3}$, Per J. Palsbøll ${ }^{3}$, Chee K. Choo ${ }^{4}$, \\ Howaida Gabr ${ }^{5}$, Sara A. Lourie ${ }^{6}$, Melchor Santos ${ }^{7}$, Anantha Sreepada ${ }^{8}$, \\ Michael I. Cherry ${ }^{1}$, Conrad A. Matthee ${ }^{1}$
${ }^{1}$ Evolutionary Genomics Group, Department of Botany and Zoology, Stellenbosch University, Matieland 7602, South Africa
${ }^{2}$ Research Division, California Academy of Sciences, Golden Gate Park, San Francisco, California 94118, USA
${ }^{3}$ Ecosystem Science Division-ESPM, University of California at Berkeley, 151 Hillgard Hall, Berkeley, California 94720-3110, USA
${ }^{4}$ Department of Fisheries and Marine Science, University College of Science and Technology Malaysia (KUSTEM), 21030, Kuala Terengganu, Malaysia
${ }^{5}$ Department of Marine Biology, Suez Canal University, Ismailia, Egypt
${ }^{6}$ Project Seahorse, Department of Biology, McGill University, 1205 Avenue Dr Penfield, Montréal, Québec H3A 1B1, Canada
${ }^{7}$ Pew Marine Conservation Project, The Marine Science Institute, University of the Philippines, Diliman, Quezon City, Philippines
${ }^{8}$ Aquaculture Laboratory, National Institute of Oceanography, Dona Paula, Goa 403 004, India
${ }^{9}$ Present address: Molecular Ecology and Systematics Group, Botany Department, Rhodes University, Grahamstown 6140, \\ South Africa
}

\begin{abstract}
Mitochondrial control region (mtDNA CR) diversity within and among 6 seahorse populations associated with the Indo-Pacific Hippocampus kuda complex (H. kuda from India, Malaysia, Indonesia and the Philippines, H. fuscus from the Red Sea and H. capensis from South Africa) was compared to determine whether there was support for the hypothesis that seahorses are able to colonize remote areas by means of rafting. Analyses performed on the data-set included phylogenetic reconstructions, estimation of relative population ages, tests for evidence of population expansion, pairwise migration rates and divergence times, as well as relationships between genetic and geographic distances. The mtDNA data indicate that all populations have undergone recent expansions, but that the timing of these events differed. The $H$. kuda population from India was found to be the oldest, whereas the expansion of the H. fuscus population from the Red Sea took place most recently. The fact that all seahorse populations studied are characterized by a single ancestral mtDNA haplotype and migration rates are low in most cases, as well as the fact that no significant relationship between genetic and geographic distances was found, indicates that colonization of distant habitats by a small number of founding individuals may be common in seahorses associated with the $H$. kuda complex. As the level of subsequent gene flow among populations is low, this may result in rapid speciation.
\end{abstract}

KEY WORDS: Hippocampus kuda $\cdot$ H. fuscus $\cdot$ H. capensis $\cdot$ Rafting $\cdot$ Founder-event $\cdot$ Speciation · Population expansion · Isolation-by-distance

Resale or republication not permitted without written consent of the publisher

\section{INTRODUCTION}

Most studies comparing the population structure of marine organisms have suggested that species with long-lived teleplanic larvae have greater dispersal abilities than species that lack larval stages (e.g. Schel- tema 1971, 1978, Hunt 1993, Russo et al. 1994). However, recent evidence indicates that some direct developers (i.e. taxa that lack larval stages) are more widely distributed than expected from their life history traits. The mechanism responsible for these high dispersal abilities is believed to be the association with rafts 
(Jokiel 1984, Johannesson 1988, Parker \& Tunnicliffe 1994, Morton \& Britton 2000, Mora 2001) such as floating seaweed (Holmquist 1994, Worcester 1994, Ingolfsson 1995, Hobday 2000). In fact, rafting may provide a more efficient means of colonizing remote areas than larval dispersal (Johannesson 1988, Helmuth et al. 1994). Successful colonization depends on a sufficiently large number of individuals arriving simultaneously in one location to establish themselves, the chances of which decrease with increasing distance from the source habitat in species that disperse by means of teleplanic larvae. In contrast, rafting provides a mechanism for a large number of conspecifics to arrive simultaneously at a new location (Stoddart 1984). As gene flow tends to be low among populations founded by direct developers, genetic structuring and the potential for speciation of isolated lineages tends to be higher than in taxa characterized by larval dispersal. Paulay \& Meyer (2002) suggested that 'founder speciation' may thus be a more important process of genetic differentiation in the sea than previously thought, and may be more common in direct developers than vicariant speciation.

Potential for long-distance dispersal by rafting has been suggested for some species of sessile invertebrates such as barnacles, gastropods, bivalves, peracarid crustaceans, corals, ascidians and echinoderms (Miller 1968, Jokiel 1984, Stoddart 1984, Highsmith 1985, Martel \& Chia 1991, Worcester 1994, Sponer \& Roy 2002, Waters \& Roy 2004). Although several teleosts have been observed associated with unattached algal clumps or other floating objects (Gooding \& Magnuson 1967, Kulczycki et al. 1981, Holmquist 1994), there is little evidence suggesting that any fish species may utilize rafting as a means of colonizing remote habitats (Kokita \& Omori 1999, Mora 2001). However, the life history traits of seahorses (Syngnathidae: Hippocampus) suggest that this mode of dispersal may be common in this teleost genus, as they share many characteristics with the above benthic invertebrates. Firstly, newborn seahorses are fully developed and start feeding immediately (Lourie et al. 1999, P.R. Teske pers. obs.), suggesting that they are unlikely to disperse over long distances as part of the plankton. Secondly, neither juvenile nor adult seahorses are strong swimmers, which suggests that they are unlikely to disperse actively. Thirdly, seahorses have a prehensile tail that is used to hold on to submerged vegetation and other objects that could serve as rafts. Sargassum weed is a favoured habitat of juvenile $H$. comes in the Philippines (Perante et al. 1998), and individuals of other species have been found among floating seaweed (Holmquist 1994, Safina 1998, Kuiter 2000).

Here we present the results of a genetic study focusing on 6 populations associated with the Indo-Pacific
Hippocampus kuda species complex which addressed the hypothesis that seahorses may disperse over great distances and colonize remote areas by means of rafting. A fully resolved phylogeny for this species complex is lacking, but genetic data so far suggest that H. kuda can be divided into 2 major lineages: the first is primarily associated with the Indian Ocean, and the second occurs in the West Pacific; this pattern is believed to be the result of a vicariance event (Teske 2003, Lourie 2004). The distributions of the 2 lineages overlap in Indonesia (Lourie 2004). The South African seahorse $H$. capensis and 2 species from the eastern Indian Ocean ( $H$. borboniensis and $H$. fuscus) are closely related to the Indian Ocean lineage of $H$. kuda, and 4 species associated with the Atlantic Ocean and the eastern and central Pacific $(H$. algiricus, $H$. reidi, $H$. ingens and $H$. hilonis) form a sister clade to the Indo-Pacific lineage (P.R. Teske unpubl. data based on mitochondrial DNA). Due to uncertainties regarding which of the Indo-Pacific assemblages are associated with the $H$. kuda complex and which are merely closely related species, we refer to all specimens other than those originating from estuaries located in the warm temperate portion of the South African coast (H. capensis) and those collected from the Red Sea (H. fuscus) as H. kuda.

The fact that the $H$. kuda complex is widely distributed throughout the Indo-Pacific (Lourie et al. 1999) and forms part of the only seahorse lineage characterized by a circumglobal distribution (Teske et al. 2004, P. R. Teske unpubl. data) suggests that dispersal abilities of these seahorses may be comparatively high, making them a suitable model to investigate the colonization-by-rafting hypothesis. The proposed mechanism of dispersal and differentiation should have several consequences in terms of genetic patterns. First, as remote habitats are likely to be colonized by a low number of founder individuals associated with a raft, each population should be characterized by a low number of ancestral alleles. Second, as additional recruitment is likely to be rare once a new population has been founded, levels of gene flow among populations should be low. Third, although geographically proximate locations have a greater chance of being colonized by both direct developers and species that have planktonic larvae than distant locations, the fact that dispersal in direct developers may occur over great distances suggests that geographic and genetic distances among populations may not be strongly correlated. In contrast to species that disperse by means of planktonic larvae, in which the probability of founding a new population decreases with increasing distance from the source area, seahorse population differentiation may not necessarily follow a model of isolation-bydistance. 


\section{MATERIALS AND METHODS}

Six populations of seahorses were sampled (24 to 38 individuals from each). Four of these were identified as Hippocampus kuda and were collected in India, Malaysia, Indonesia and the Philippines. The closely related species $H$. capensis from South Africa and $H$. fuscus from the Red Sea were also sampled. A limited number of individuals from an additional 7 geographic localities were included to provide a spatial perspective (Fig. 1). Fin clips were used whenever possible (Table 1), and the captured seahorses were subsequently released. The right domain of the mitochondrial control region (CR) was sequenced in a total of 224 specimens (Table 1). DNA extraction and amplification of CR sequences followed the methodology published previously (Teske et al. 2003). Sequences were aligned in ClustalX (Thompson et al. 1997) using default parameters, and a homologous region of $380 \mathrm{nu}$ cleotides was obtained for all individuals. All haplotypes generated in this study were submitted to GenBank (accession numbers AY642329 to AY642380).

Phylogenetic analysis. Phylogenetic relationships among all seahorse CR sequences were estimated using the neighbour-joining method (Saitou \& Nei 1987). Pairwise distances among haplotypes were estimated in PAUP* Version $4.0 \mathrm{~b} 10$
Table 1. Hippocampus spp. A list of the seahorse specimens used in this study, including sampling locations and sample sizes. Based on phylogenetic information (see 'Results'), $H$. kuda samples from 9 of the sampling locations were each assigned to one of 3 regional lineages: samples from Tamil Nadu (southeastern India) and the Goa and Ratnagiri estuaries (western India) comprised H. kuda (India); samples from North Sulawesi (excluding 2 specimens associated with the West Pacific lineage of $H$. kuda, i.e. $\mathrm{N}=22)$ and Lombok $(\mathrm{N}=2)$ comprised H. kuda (Indonesia); and samples from KwaZulu/Natal (South Africa), Inhaca Island (Mozambique) and Pemba (Tanzania) comprised H. kuda (SE Africa). In some analyses, only 35 of the 38 specimens collected in the Philippines were included, as 3 specimens were associated with the Indian Ocean lineage of $H$. kuda. Complete specimens were available from samples marked with asterisks. All other samples were fin clips

\begin{tabular}{|llc|}
\hline Species & Sampling location & $\begin{array}{c}\text { Sample } \\
\text { size (N) }\end{array}$ \\
\hline H. kuda & Tamil Nadu, southeastern India & 24 \\
& Goa and Ratnagiri estuaries, western India & 11 \\
& Pulai Estuary, Johor, Peninsular Malaysia & 35 \\
& Lombon Sulawesi, Indonesia & $22(+2)$ \\
& KwaZulu/Natal, South Africa* & 2 \\
& Inhaca Island, Mozambique & 3 \\
H. kuda & Pemba, Tanzania* & 2 \\
(West Pacific lineage) & Tayabas Bay, Quezon, the Philippines & 1 \\
& Fiji & $35(+3)$ \\
H. fuscus & Taiwan* & 10 \\
H. capensis & Gulf of Suez, Red Sea, Egypt* & 1 \\
& Knysna Estuary, South Africa & 35 \\
Outgroup & & 35 \\
H. reidi & & \\
H. ingens & Gulf of Mexico, Mexico* & 1 \\
H. hilonis & East Pacific coast, Mexico* & 1 \\
\hline
\end{tabular}

(Swofford 2002) using default settings and employing a distance model selected using the hierarchical likelihood ratio test and the AIC criterion implemented in

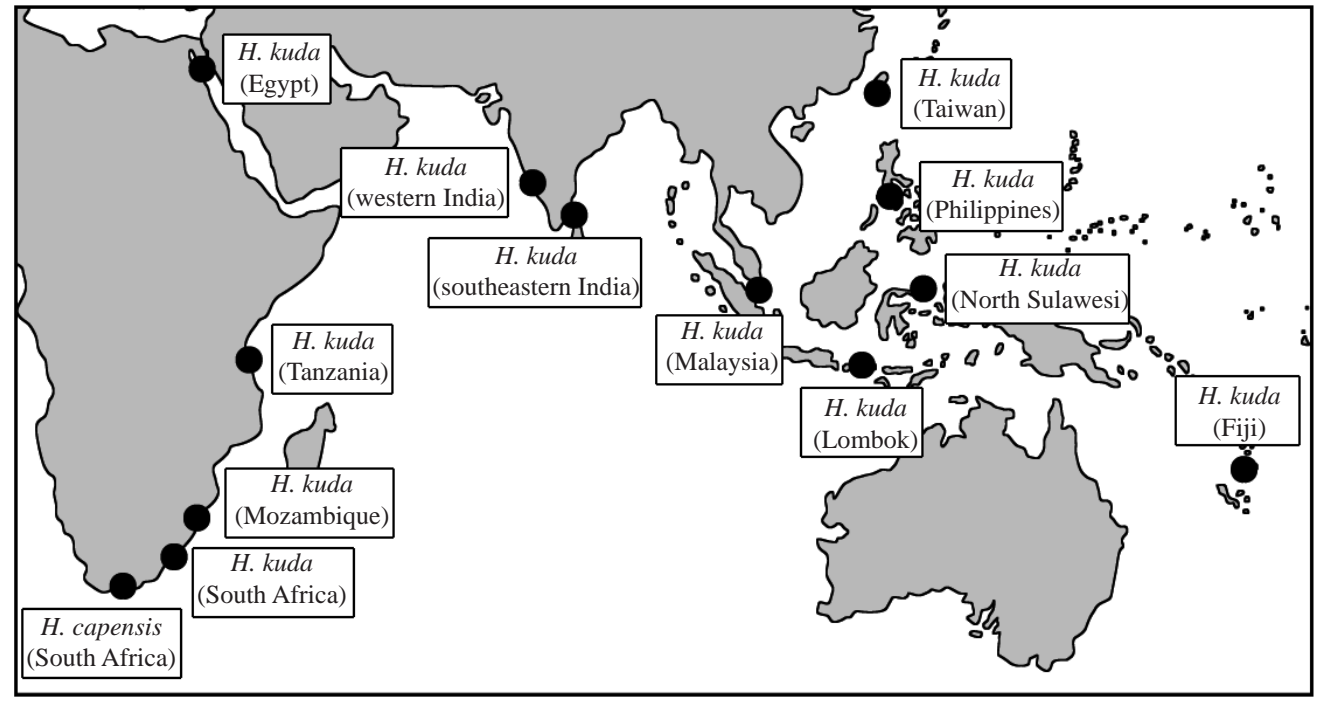

Fig. 1. Geographic localities from which samples of seahorses associated with the Hippocampus kuda complex were included in this study 
the program MODELTEST version 3.06 (Posada \& Crandall 1998). The tree was rooted with an outgroup comprising 3 geographically distant seahorse species that are closely related to the Indo-Pacific lineages focused on in the present study (Hippocampus reidi from the West Atlantic, $H$. ingens from the East Pacific and $H$. hilonis from Hawaii; P. R. Teske unpubl. data). Gaps were treated as missing characters and support for nodes on the tree was obtained from 1000 bootstrap replicates.

Minimum spanning networks. The program TCS version 1.06 (Clement et al. 2000) was used to estimate minimum spanning networks of CR sequences from the 6 individual populations. TCS estimates genealogies by implementing the statistical parsimony method described in Templeton et al. (1992). The program also uses the criteria in Crandall \& Templeton (1993) and Castelloe \& Templeton (1994) to identify a haplotype network's oldest haplotype (the 'ancestral-' or 'roothaplotype') under the assumption of neutrality and homogenous sampling (D. Posada pers. comm.). This is achieved by calculating each haplotype's 'outgroup weight' by incorporating its frequency, its distance from the mid-point of the cladogram, and the number of connections with neighbouring haplotypes, and then selecting the haplotype with the highest outgroup weight. All gaps were single base-pairs in length and in this case were coded as a fifth character.

Demographic statistics. The program DNASP version 4.00 (Rozas \& Rozas 1999) was used to obtain estimates of nucleotide diversity $(\pi)$ and haplotype diversity $(h)$, and relative population ages were estimated by calculating the timing of demographic expansion $(\tau)$ based on the number of pairwise differences between sequences (mismatch distribution; Slatkin \& Hudson 1991, Rogers \& Harpending 1992) using default parameters. To test for departure from the expectations of the sudden expansion model, Harpending's raggedness index (HRI) was estimated in ARLEQUIN version 2.001 (Schneider et al. 2000, including 2 updated files that were released in 2001). In all analyses, alignment gaps were treated as missing data.

Analyses of gene flow. The predicted pattern of genetic divergence under the colonization-by-rafting hypothesis could be produced by one of 2 processes: (1) recent complete isolation, or (2) historical separation with limited gene flow. In order to distinguish between isolation and gene flow as forces shaping the patterns of genetic diversity in the sampled seahorse populations, we analyzed the CR data using the program MDIV (Nielsen \& Wakeley 2001). MDIV allows the estimation of the parameters $\theta\left(2 N_{\mathrm{f}} \mu\right.$, where $N_{\mathrm{f}}$ is the effective female population size and $\mu$ is the mutation rate), $T\left(t / 2 N_{\mathrm{f}}\right.$, where $t$ is the divergence time) and $M\left(2 N_{\mathrm{f}} m\right.$, where $m$ is the migration rate) between
2 populations using a Markov chain Monte Carlo method. Pairwise comparisons were made among all 6 seahorse populations, and in addition, samples of Hippocampus kuda from Tanzania, Mozambique and South Africa were pooled to represent a 7th, southeast African population. Several test runs were conducted to assess the appropriate upper bounds of each parameter estimated, which were $M=0.5$ and $T=10$. All estimations were conducted assuming an HKY mutation model (Hasegawa et al. 1985, Palsbøll et al. 2004), and each run comprised 5000000 cycles and included a burn-in of 500000 cycles. Three independent runs were conducted with different random starting seeds for each of the pair-wise comparisons.

The relationship between genetic and geographic distance among populations associated with the Indian Ocean/Indonesian lineage was investigated by performing a Mantel permutation test (Mantel 1967). The population from the Philippines was excluded in this case, because the majority of the individuals sampled were associated with the West Pacific/Indonesian lineage of Hippocampus kuda (see 'Results'), which is genetically very different from the other assemblages investigated because of an assumed vicariance event (Teske 2003, Lourie 2004). For the same reason, 2 specimens from North Sulawesi were excluded (see 'Results'). Mantel tests were performed with MANTEL version 1.11 (Cavalcanti 1988-2000) using 10000 permutations as recommended by Jackson \& Somers (1989). The 2 matrices analysed comprised (1) $\Phi_{\mathrm{ST}}$ values (Excoffier et al. 1992) estimated as a measure of genetic distance for population pairs and (2) the geographic distance separating each pair. $\Phi_{\mathrm{ST}}$ values were calculated in ARLEQUIN under a distance model selected for a data-set including the 6 populations associated with the Indian Ocean/Indonesian lineage using the hierarchical likelihood ratio test and the AIC criterion implemented in MODELTEST. Geographic distances were rough estimates based on 2 alternative methods: (1) the shortest possible connection between 2 localities was estimated taking into account the outlines of land masses, and relationships between $\Phi_{\mathrm{ST}}$ values and geographic distances were estimated by including and excluding the supposedly distinct species $H$. capensis and $H$. fuscus and (2) information on present day surface currents within the Indian Ocean and the Indonesian seas was incorporated into distance measures (Tomczak \& Godfrey 2003). For example, the geographic distance between $H$. fuscus (Red Sea) and H. kuda (Malaysia) was estimated by following the path of the North Equatorial Current. In this case, relationships were estimated by including and excluding $H$. capensis and $H$. kuda (southeast Africa) from the data-base, because surface currents along the East African coast flow in a southward direction only 
south of Tanzania, suggesting that gene flow in this region can only be unidirectional.

\section{RESULTS}

The neighbour-joining tree (Fig. 2) recovered 2 major lineages. One of these comprises populations associated with the West Pacific/Indonesian lineage of Hippocampus kuda (Philippines, Taiwan, Fiji and North Sulawesi) and the other represents the Indian Ocean/Indonesian lineage ( $H$. kuda from India, southeastern Africa, Malaysia, North Sulawesi and other parts of Southeast Asia, as well as H. fuscus from the

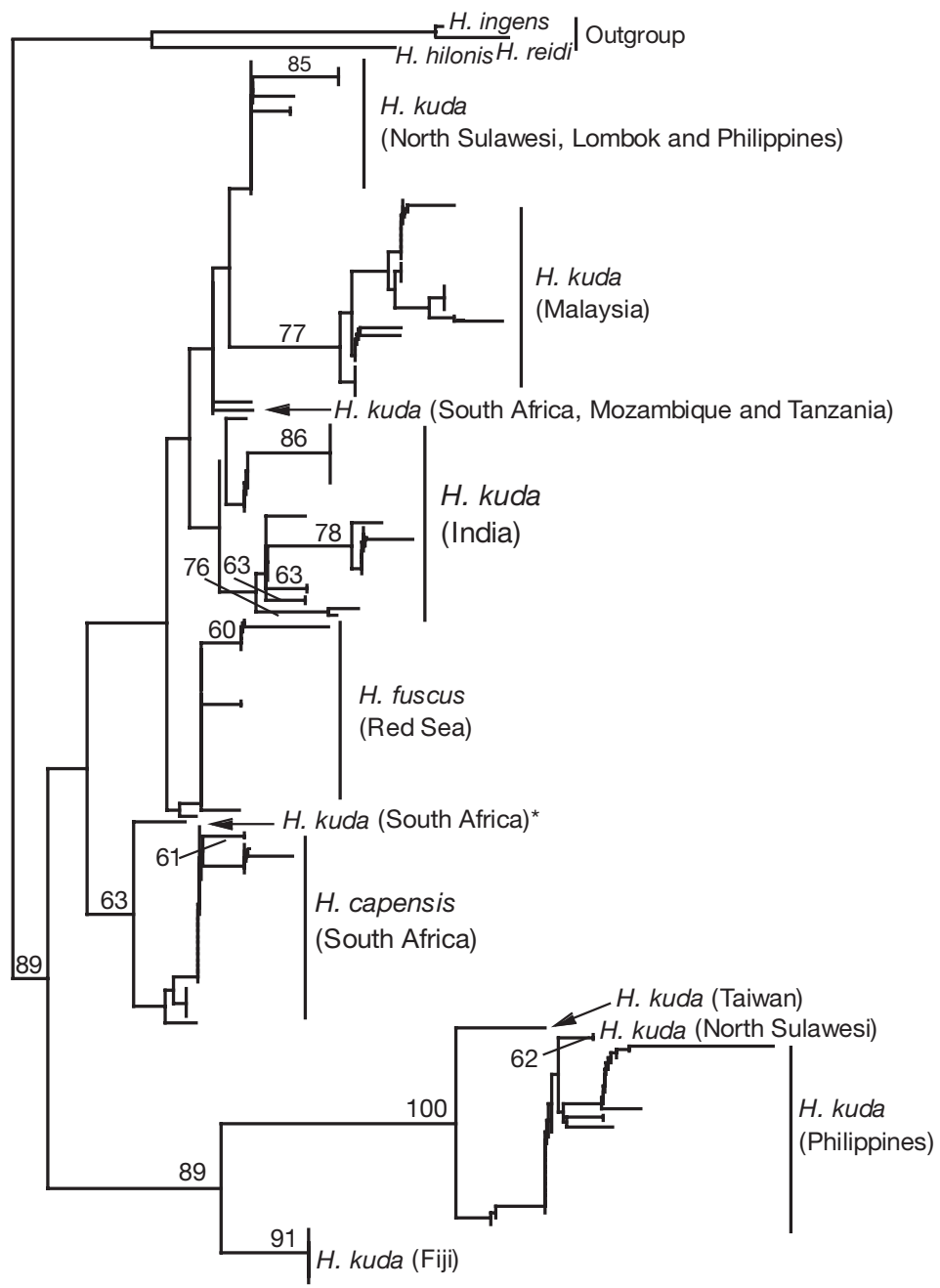

Fig. 2. Hippocampus spp. A neighbour-joining phylogram constructed from pairwise GTR + I+ G distances (Rodríguez et al. 1990) of all 221 ingroup CR sequences generated in this study, as well as 3 outgroup sequences. The substitution model incorporated an assumed proportion of invariable sites of 0.62 and a gamma shape distribution parameter $\alpha=1.06$. Nodal support from 1000 bootstrap replications ( $\geq 60 \%)$ is shown above some branches. The H. kuda specimen from South Africa marked with an asterisk is shown in Fig. 4b
Red Sea and H. capensis from South Africa). The 6 populations were each recovered as monophyletic lineages, except that a haplotype represented by 2 specimens from North Sulawesi (Indonesia) clustered among haplotypes dominating the population from the Philippines, and 3 specimens from the Philippines had the same haplotype as 16 individuals collected in North Sulawesi and one of the 2 specimens from Lombok. As the haplotypes of the 2 specimens from Lombok (southern Indonesia) both clustered with haplotypes from North Sulawesi (northeastern Indonesia), they were added to the latter population, which is referred to as H. kuda (Indonesia). Genetic divergences among most of the different seahorse lineages were minimal, and relatively few clades had high ( $\geq 75 \%$ ) bootstrap support.

TCS networks incorporating allele frequencies constructed for individual populations were all characterized by a star-like phylogeny, with a single, pivotal haplotype (identified as the 'ancestral-' or 'root-haplotype' of the network based on the criteria in Crandall \& Templeton 1993 and Castelloe \& Templeton 1994) that had given rise to several derived haplotypes (Fig. 3). The haplotypes identified as ancestral were numerically dominant in each of the populations, with the exception of the Indian assemblage (Fig. 3f). A star-like phylogeny is indicative of rapid population expansion, and populations characterized by a highly abundant root-haplotype and many closely associated rare haplotypes are younger and are expanding more rapidly than populations characterized by a less abundant roothaplotype and derived haplotypes that differ from it by several nucleotide substitutions and are comparatively less rare (Slatkin \& Hudson 1991). Based on this reasoning, the networks in Fig. 3 are tentatively arranged in the approximate order of increasing age: the population of Hippocampus fuscus from the Red Sea is characterized by a highly abundant ancestral haplotype and relatively few derived haplotypes (present at low frequency), which is indicative of a very recent population expansion, whereas the Indian population of $H$. kuda is comparatively more stable and the expansion event was longer ago. Only 2 haplotypes were found among 11 seahorses originating from western India (Goa and Ratnagiri estuaries), as compared to 10 haplotypes among 24 specimens from southeastern India. The haplotype identified as the root of the network in Fig. 3f was present in both western and southeastern India, which gives further credence to the 


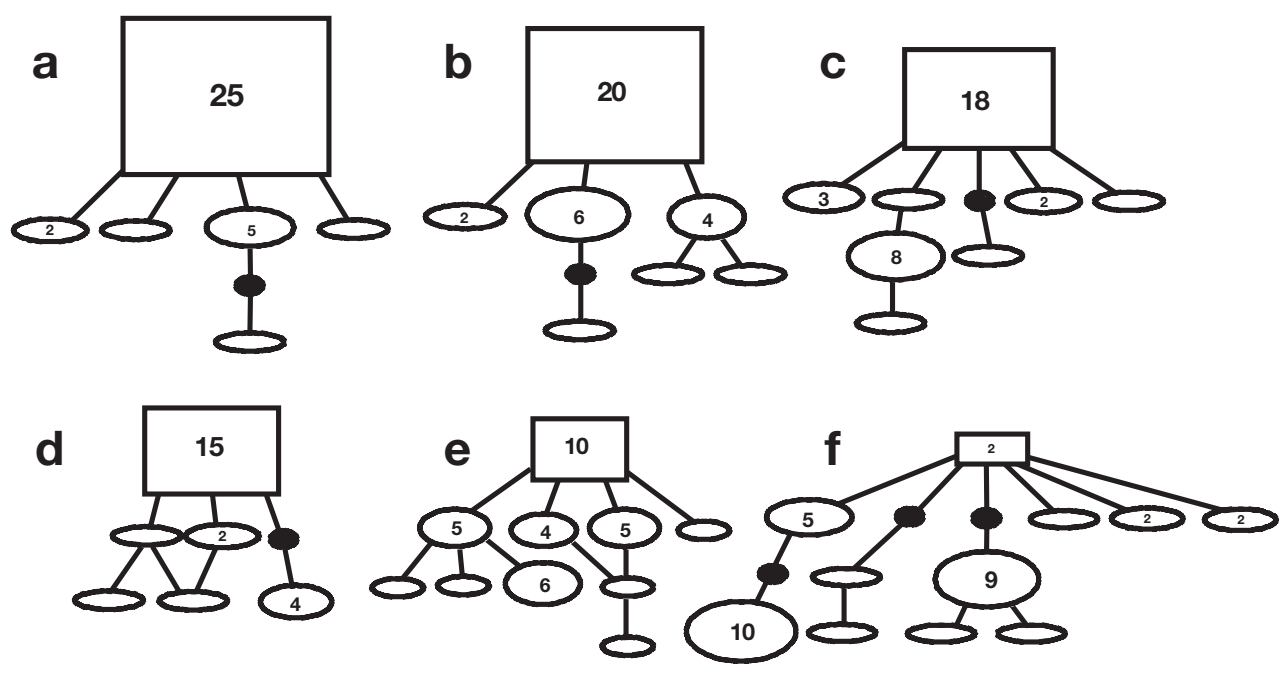

Fig. 3. Hippocampus spp. TCS haplotype networks of 6 seahorse populations. Squares represent each population's root-haplotype and ovals represent derived haplotypes. The frequency of haplotypes represented by more than 1 individual is indicated by a number. Black ovals represent interior node haplotypes not present in the samples. Networks are arranged according to the approximate relative age of the populations, i.e. the numerical dominance of the root haplotype decreases, and the number and frequency of derived haplotypes increases; (a) H. fuscus (Egypt); (b) H. capensis (South Africa); (c) H. kuda (Philippines); (d) H. kuda (Indonesia); (e) H. kuda (Malaysia); (f) H. kuda (India). The 2 haplotypes present in western India were the root-haplotype and the derived haplotype present in 10 individuals. Haplotype networks (a)-(c) and (e)-(f) were constructed using 35 individuals, and network d comprised 24 individuals. Haplotypes associated with a lineage distantly related to the other haplotypes in the population (i.e. Indian Ocean haplotypes in the population from the Philippines and West Pacific haplotypes in the population from North Sulawesi, refer to Table 1) are not included

notion that this haplotype is the oldest, despite its low frequency (Crandall \& Templeton 1993).

Statistical parameters comparing the different populations are listed in Table 2. The number of haplotypes recovered differs from those recovered in Fig. 3 in 3 cases, as gaps were not treated as fifth characters: Hippocampus kuda (Philippines): 7 instead of $8 ; H$. kuda (Indonesia): 4 instead of 6 ; and $H$. capensis: 6 instead of 7. However, the general results are similar in that the Indian and Malaysian populations are characterized

Table 2. Hippocampus kuda complex. Population genetic parameters estimated for 6 seahorse populations. In addition, samples from Tamil Nadu (southeastern India) are shown separately because of a distinct difference in the number of haplotypes present compared to western India. N: sample size; H: number of haplotypes (gaps were coded as missing data); $h$ : haplotype diversity $( \pm \mathrm{SD})_{i} \pi$ : nucleotide diversity $( \pm \mathrm{SD})$; HRI: Harpending's raggedness index (a significant HRI test indicates departure from the sudden expansion model); $\tau$ : expansion time expressed in units of mutation rate $(\tau=2 u t$, where $u$ is the CR mutation rate and $t$ is the number of generations since expansion)

\begin{tabular}{|lrrcccc|}
\hline Population & $\mathrm{N}$ & $\mathrm{H}$ & \multicolumn{1}{c}{$h$} & $\pi$ & $\mathrm{p}$ (HRI) & $\tau$ \\
\hline H. kuda (India) & 35 & 11 & $0.84 \pm 0.04$ & $0.0076 \pm 0.0005$ & 0.09 & 2.32 \\
H. kuda (Malaysia) & 35 & 10 & $0.86 \pm 0.03$ & $0.0037 \pm 0.0004$ & 0.07 & 1.50 \\
H. kuda (Philippines) & 35 & 7 & $0.68 \pm 0.07$ & $0.0025 \pm 0.0004$ & 0.09 & 0.92 \\
H. capensis (South Africa) & 35 & 6 & $0.64 \pm 0.08$ & $0.0022 \pm 0.0004$ & 0.16 & 0.85 \\
H. fuscus (Egypt) & 35 & 6 & $0.48 \pm 0.10$ & $0.0017 \pm 0.0005$ & 0.47 & 0.44 \\
H. kuda (Indonesia) & 24 & 4 & $0.48 \pm 0.11$ & $0.0024 \pm 0.0006$ & 0.64 & 0.48 \\
H. kuda (Tamil Nadu) & 24 & 10 & $0.84 \pm 0.06$ & $0.0063 \pm 0.0006$ & 0.09 & 2.40 \\
\hline
\end{tabular}

by the highest number of haplotypes. Consequently, haplotype diversity indices are also high for these 2 populations. Nucleotide diversity is considerably higher for $H$. kuda (India) than for $H$. kuda (Malaysia), as the haplotypes comprising the latter population are more closely related to each other. Lowest nucleotide diversity indices were found for $H$. kuda (Philippines), $H$. fuscus and the $H$. capensis populations, as most haplotypes differed from each other by no more than 2 nucleotide substitutions. Signatures of population expansion in all 6 populations were also suggested by Harpending's raggedness statistic (HRI): none of the p-values was significant, which indicates that the sudden expansion model was not rejected for any of the populations. The $p$-values were highest for $H$. fuscus (Egypt) and H. kuda (Indonesia) and were marginally nonsignificant in the case of $H$. kuda (Malaysia), H. kuda (Philippines) and $H$. kuda (India). The statistic $\tau$, which indicates of how long ago a population expansion took place, was highest for $H$. kuda (India), but was also fairly high for $H$. kuda (Malaysia). The 
$H$. fuscus population had the lowest value of $\tau$, indicating that this population expanded comparatively recently. Due to the difference in the number of haplotypes between the populations from the western and southeastern coasts of India, demographic parameters for the population from Tamil Nadu (southeastern India) are shown separately. Despite the lower sample size $(\mathrm{N}=24)$, all parameters were similar or identical to those based on the complete data-set of $H$. kuda (India).

The MDIV results indicate little to no gene flow among most of the sampled seahorse populations (Table 3). Comparatively high values of gene flow were estimated in pairwise comparisons between Hippocampus kuda from southeastern Africa and $H$. kuda from Indonesia, $H$. fuscus from Egypt, and $H$. capensis from South Africa. In contrast, low rates of gene flow were observed among the majority of comparisons including $H$. kuda (Philippines) and $H$. capensis. Note, however, that in order to compare relative divergence times among the 7 assemblages, samples that were distantly related to the dominant lineage in a particular region (i.e. 2 specimens in the Indonesian population having West Pacific haplotypes, and 3 specimens in the population from the Philippines having Indian Ocean haplotypes) were excluded in Table 3. When these samples were included, the migration rate between these 2 populations was the highest found overall, 0.195. Divergence times were highest in comparisons including $H$. kuda from the Philippines. The second highest value was found between this population and $H$. kuda from Indonesia (when recent migrants were included, this value increased to 14.2), which suggests that despite geographical proximity, these 2 populations did not diverge from each other more recently than any of the other assemblages associated with the Indian Ocean diverged from the West Pacific population from the Philippines. Lowest divergence times were found in comparisons between $H$. kuda from southeastern Africa and H. kuda (Indonesia), H. fuscus and H. capensis.

Table 3. Results of MDIV analyses. Above diagonal: migration rates; below diagonal: relative population divergence time in units of $\mu t$, where $\mu$ is the per nucleotide mutation rate and $t$ the number of generations. Values shown for each pairwise comparison are means from 3 independent runs

\begin{tabular}{|c|c|c|c|c|c|c|c|c|}
\hline Species & Region & 1 & 2 & 3 & 4 & 5 & 6 & 7 \\
\hline 1 H. kuda & India & & 0.060 & 0.003 & 0.037 & 0.002 & 0.021 & 0.001 \\
\hline 2 H. kuda & Indonesia & 1.9 & & 0.001 & 0.080 & 0.003 & 0.015 & 0.001 \\
\hline 3 H. kuda & Malaysia & 3.1 & 1.5 & & 0.018 & 0.003 & 0.006 & 0.001 \\
\hline 4 H. kuda & SE Africa & 2.2 & 0.9 & 2.3 & & 0.001 & 0.130 & 0.070 \\
\hline 5 H. kuda & Philippines & 5.9 & 6.8 & 7.7 & 6.2 & & 0.001 & 0.001 \\
\hline 6 H. fuscus & Egypt & 2.0 & 1.7 & 2.6 & 1.0 & 5.9 & & 0.004 \\
\hline 7 H. capensis & South Africa & 3.1 & 3.1 & 4.4 & 1.3 & 6.7 & 2.2 & \\
\hline
\end{tabular}

The program MODELTEST selected the Tamura Nei model (Tamura \& Nei 1993; including a proportion of invariable sites of 0.8 ) as the optimal model of nucleotide substitution for seahorse populations associated with the Indian Ocean/Indonesian lineage. Relationships between $\Phi_{\mathrm{ST}}$ (estimated using genetic distances based on the above substitution model) vs. geographic distance were not significant, irrespective of whether geographic distances were based on the shortest possible distances between 2 locations and Hippocampus capensis and $H$. fuscus were included or excluded $(t$ [approximate Mantel $t$-test] $=1.674, \mathrm{p}$ [probability that random Mantel statistic $Z<$ observed $Z]=0.953$ and $t=-0.996, \mathrm{p}=0.160$, respectively), or whether present-day ocean currents were taken into account and $H$. capensis and $H$. kuda (SE Africa) were included or excluded $(t=0.579, \mathrm{p}=0.719$ and $t=0.831$, $\mathrm{p}=0.797$, respectively)

\section{DISCUSSION}

\section{Evidence for long-distance dispersal by rafting}

All 6 seahorse populations investigated were characterized by ancestral monophyly (the presence of a single basal haplotype that has given rise to several derived haplotypes) and recent population expansions, suggesting that they were founded by few individuals and then rapidly increased in population size. The fact that male seahorses store fertilized eggs in a brood pouch suggests that single displaced gravid individuals can theoretically act as founders. The presence of a single ancestral allele in each population may be explained by the fact that the offspring of a single individual all inherit the same mitochondrial haplotype from their mother.

The notion that populations founded by a low number of rafting individuals will subsequently receive few additional recruits was confirmed in the case of populations associated with the Indian Ocean, where no haplotypes were shared among populations, and which were characterized by low migration rates. Although most of the pairwise estimates of gene flow suggested a small but measurable amount of migration between populations, all population comparisons suggested migration rates below 1 per generation, the theoretical rate of gene flow required to prevent 2 populations from diverging (Wright 1931). These results suggest that the 
Indian Ocean lineage of Hippocampus kuda is not a panmictic population, but rather an assemblage of regional lineages. It is likely that the populations sampled for this study represent only a fraction of all the monophyletic lineages present in the region. In contrast, levels of gene flow among populations appear to be higher in the eastern portion of Southeast Asia (represented by samples from Indonesia and the Philippines), which is characterized by high current velocities (Wyrtki 1961, Godfrey 1996), and where there was evidence for a mixture of genetically very distantly related lineages.

The lack of correlation between genetic and geographic distances among populations associated with the Indian Ocean/Indonesian lineage may be an indication that dispersal over great distances is common in this assemblage. However, Sponer \& Roy (2002) found that population differentiation of the rafting brittle star Amphipholis squamata along the coast of New Zealand does follow a model of isolation-by-distance and Lourie (2004) found isolation-by-distance among southeast Asian seahorse populations. This suggests that such a pattern may emerge in seahorses associated with the Indian Ocean on a smaller geographic scale (e.g. along the east coast of Africa), but it may be less likely when dispersal has taken place at a transoceanic scale and was influenced by strong ocean currents. Nevertheless, the lack of correlation found in this study may be the result of low statistical power, and the inclusion of additional populations and additional loci may result in firmer conclusions. Although it is presently unknown how long a displaced seahorse would survive on its raft, the fact that macrobenthos may be very abundant on floating algae (Gore et al. 1981, Virnstein \& Howard 1987, Holmquist 1994) suggests that it may serve as food for a displaced seahorse and enable it to survive for a prolonged period of time until a new habitat is reached. Holmquist (1994) showed that rafting animals are more likely to remain associated with drifting algae if the surrounding habitat is unfavourable (e.g. characterized by an absence of vegetation), and hence a rafting seahorse is likely to hold on to its raft until it has reached a suitable habitat.

\section{Population comparisons}

Estimates of $\tau$ and divergence time obtained in this study do not seem suitable to determine exact population ages. Results are based on a single locus only, and as sampling sizes were fairly small, it is likely that only a fraction of the haplotypes present within each population was recovered. A case in point is the Hippocampus capensis population: in a previous study based on 138 specimens (Teske et al. 2003), a total of 15 CR haplo- types were recovered. In the present study, only 6 haplotypes were found among 35 specimens that were randomly selected from the original dataset (or 7 when gaps were coded as fifth characters). Nevertheless, the values calculated may be suitable to compare relative population ages. The $H$. fuscus population from the Red Sea was characterized by the most recent expansion event. A possible age estimate for this population is $10000 \mathrm{yr}$, which is based on the following reasoning. The Red Sea was isolated from the Indian Ocean during the last ice age and during that time was characterized by cool water and high salinity (Por 1978). Although it cannot be ruled out that some seahorses survived these conditions, the fact that seahorses associated with the $H$. kuda complex are mostly restricted to tropical and sub-tropical regions (Lourie et al. 1999) suggests that they were not present in the Red Sea during that time. It seems appropriate to place the age of the H. fuscus population at the beginning of the present interglacial, approximately 10000 yr ago, when the Red Sea became reconnected to the Indian Ocean, environmental conditions changed, and the region was colonized by species from the adjacent Indian Ocean (Goren 1986), a scenario that is supported by the comparatively small divergence time estimated for $H$. fuscus and $H$. kuda from southeastern Africa. On the opposite end of the scale is the $H$. kuda population from India, which was not dominated numerically by an ancestral haplotype, and which was characterized by the greatest number of nucleotide substitutions between oldest and youngest haplotypes. Although a signature of population expansion is still present, this population is comparatively older and more stable than the other populations investigated. A $\tau$ value considerably higher than that of the $H$. fuscus population indicates that this assemblage is likely to have been founded prior to the beginning of the present interglacial. As sea surface temperatures in the Indian Ocean were no more than $2.5^{\circ} \mathrm{C}$ lower during the last ice age than they are today (Bard 2003), environmental conditions throughout the equatorial regions of the Indian Ocean may have been favourable for seahorses throughout the last glacial and interglacial phases. It may thus be reasonable to assume that $H$. kuda was present along the coastline of India throughout or perhaps even prior to the last ice age, and founding events of some of the other $H$. kuda populations elsewhere in the Indian Ocean and the West Pacific may also have been fairly independent of glacial cycles. The population from Fiji may be an exception, as the low genetic diversity (all 10 individuals had the same haplotype) may be an indication that this region was colonized recently. However, the older age of the Indian population is not an indication that the Indian Ocean lineage of $H$. kuda originated in this region. Demographic parameters suggest that this population 
is not substantially older than other populations, and the oldest haplotype of the Indian assemblage is not basal to any haplotypes of the other populations of $H$. kuda. The high genetic diversity in Tamil Nadu (southeastern India) may merely be the result of long-term stable environmental conditions in this region. In contrast, 11 individuals collected in the Goa and Ratnagiri Estuaries in western India had only 2 haplotypes. This striking difference in genetic diversity between southeastern and western India may be due to the substantial coastal cold-water upwelling events characteristic of western India (Shetye et al. 1991, Madhupratap et al. 2001). The drastic decrease in water temperature associated with upwelling is known to negatively affect the survival and dispersal of tropical marine species (Fleminger 1986, Maree et al. 2000, Bowen et al. 2001), and it is possible that seahorse population sizes in western India fluctuate considerably. They may either go through genetic bottlenecks or become extinct, in which case the presence of comparatively few haplotypes in this region (one of which was also found in southeastern India) may be an indication that western India is sporadically (re)colonized by seahorses from southern or southeastern India.

\section{Taxonomic issues}

Uncertain species boundaries and the occurrence of species complexes are common problems associated with the systematics of marine organisms (Knowlton 1993, Avise 1994, Gosling 1994). The Hippocampus kuda complex presents a case in point. Based on limited morphological data, Lourie et al. (1999) found that at least 15 species names were merely synonyms for H. kuda, and 6 species that had been considered part of this species complex are likely to be independent species. Lourie et al. (1999) considered the distribution of $H$. kuda to encompass the Indian subcontinent, Thailand, Singapore, Vietnam, Hong Kong, Taiwan, the Philippines, Malaysia, Indonesia, Japan, as well as possibly northern Australia and some Pacific islands. Kuiter (2000), on the other hand, restricted the species' distribution to the Maldives, Sri Lanka, Andaman Sea, Singapore and western Indonesia to Ryukyus, Japan. Several seahorses regarded as $H$. kuda by Lourie et al. (1999) are given species status by Kuiter (2000), including $H$. arnei (southern China Seas and Philippines), H. moluccensis (Ambon and eastern Sulawesi), $H$. polytaenia (Flores Sea, and H. taeniopterus (Moluccen Sea to Sulawesi and Bali). Neither author mentions the presence of $H$. kuda on the east coast of Africa, whereas Dawson (1986) states that the species occurs in Mozambique and Kenya. Lourie et al. (1999) report the presence of $H$. borboniensis and possibly also $H$. fuscus in this region, whereas Kuiter (2000) considers only $H$. borboniensis a western Indian Ocean species, and restricts the distribution of $H$. fuscus to the Red Sea and Arabian seas.

The confusion regarding the taxonomy of the Hippocampus kuda complex can possibly be explained by the potential for lineages that have arisen because of a founder event to rapidly diverge from their sister lineages. Mayr $(1954,1963)$ formulated a speciation model according to which the probability of speciation is enhanced when a few migrant individuals colonizing a new habitat start a new population. Genetic structuring of the population is likely to ensue as it adapts to its new habitat under the conditions of genetic depauperation caused by the founder event. The model has been criticized (Lande 1980, Barton \& Charlesworth 1984, Rice \& Hostert 1993, Coyne 1994) and it is disputed whether laboratory experiments have succeeded in corroborating it (Ringo et al. 1985, Moya et al. 1995, Templeton 1999), but it nevertheless remains possible that new species arise quickly from populations established by a small number of founders in remote and isolated habitats (Moya et al. 1995). Templeton $(1980,1981)$ expressed founder-effect speciation in genetic terms, which he termed 'genetic transilience'. A population that develops after a founder event usually differs considerably in genetic composition from its ancestral population and as the genetic bottleneck can lead to an accumulation of inbreeding, alleles are likely to be selected for their homozygous fitness effects (selective bottleneck). In this way, genetic transilience may lead directly to changes in morphology, physiology, life history and development. Carson (1975) suggested that the number of loci affected by founder-effect speciation may be relatively small, as it does not involve alleles that are not affected by selection pressure. If the speciation event is relatively recent, few differences may thus be detected among 2 sister species at the CR level.

The results of the present study indicate that although the different populations associated with each of the 2 major lineages of the Hippocampus kuda complex are closely related to each other, the fact that each population studied was characterized by ancestral monophyly and levels of gene flow were low, gives some credence to Kuiter's (2000) approach of dividing the $H$. kuda complex into a number of regional lineages. However, it is as yet not resolved how well the mitochondrial lineages identified in this study correspond to the species accepted as valid by Kuiter (2000), and whether they are reproductively isolated from each other. In the absence of more comprehensive data from the region, it may be appropriate to treat regional populations of $H$. kuda as individual management units (Moritz 1994) rather than distinct species. 
The potential for rapid speciation may explain why the relatively young Hippocampus capensis (South Africa) and $H$. fuscus (Red Sea) assemblages are characterized by similar (but probably convergent) morphological features (Fig. 4c,d). The morphologically very different $H$. kuda (or $H$. borboniensis) specimen from Durban harbour (Fig. 4b) was genetically most closely associated with the $H$. capensis population (Fig. 2). It is unlikely that this specimen represents a

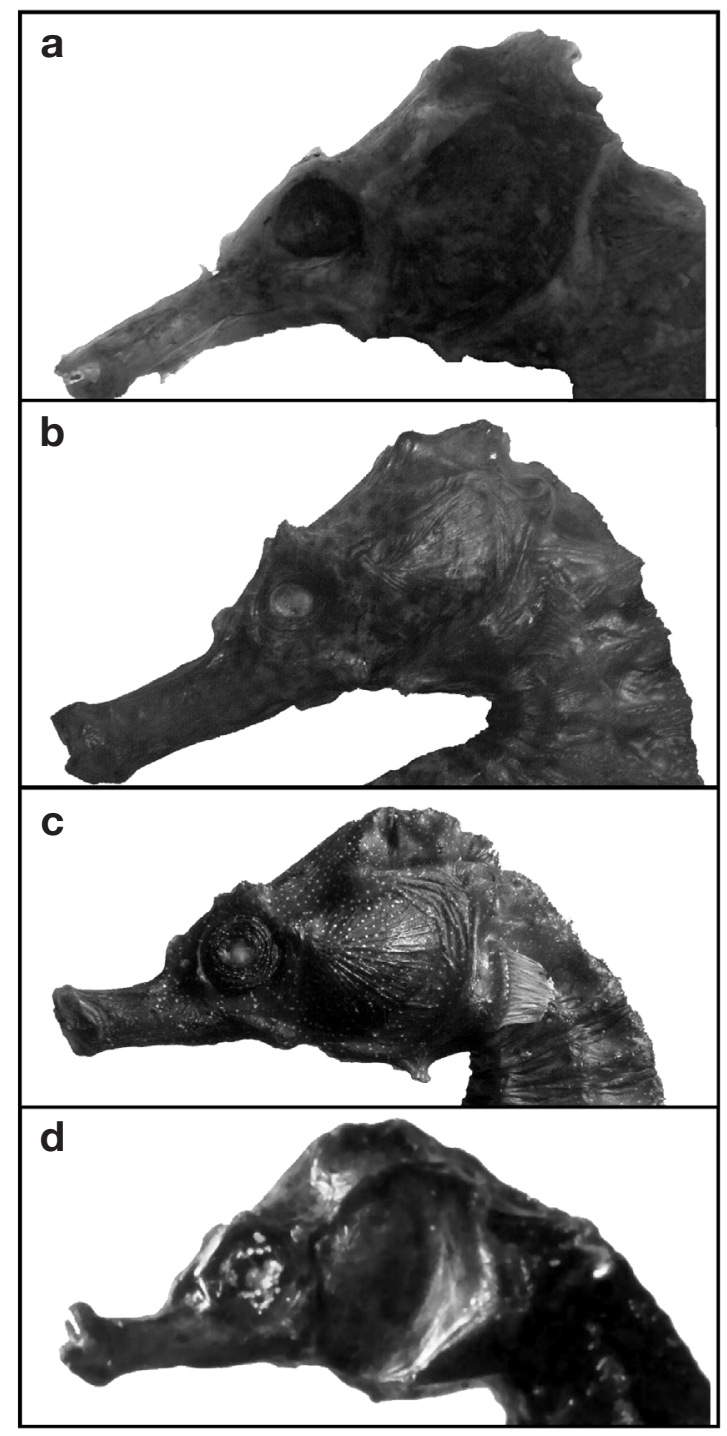

Fig. 4. Hippocampus spp. Comparison of the head morphologies of 4 adult seahorse specimens; (a) $H$. kuda or $H$. borboniensis (Inhaca Island, Mozambique); (b) H. kuda or H. borboniensis (Durban harbour, South Africa); (c) H. fuscus (Gulf of Suez, Egypt); (d) H. capensis (Knysna Estuary, South Africa). Specimens (a) and (b) are characterized by a longer snout as compared to specimens (c) and (d). A distinct coronet (crest on top of the head) is present in specimens (a) and (b), which in specimens (c) and (d) is reduced to a keel hybrid of $H$. kuda and $H$. capensis that arose as a result of gene flow of $H$. capensis from South Africa's south coast to the east coast, because such migrants would have had to swim against the southwards flowing Agulhas Current. Similar morphological characters in $H$. capensis and $H$. fuscus seem to have evolved independently, possibly because of adaptations to similar environmental conditions: like the South African estuaries inhabited by $H$. capensis, the northern Red Sea is characterized by dense seagrass beds (Lipkin 1977, Jacobs \& Dicks 1985) where a shorter snout and a reduced coronet may be advantageous to avoid entanglement. Given the potential for rapid speciation in seahorses associated with the $H$. kuda complex, we tentatively conclude that $H$. capensis and $H$. fuscus should be considered distinct taxonomic entities/species, despite the fact that both appear to have diverged from their respective sister taxa relatively recently. However, accepting the species status of $H$. capensis and $H$. fuscus has important implications for the taxonomy of the entire $H$. kuda complex: it is possible that several other lineages associated with this species complex could also be considered distinct species, and of particular importance in this respect is the fact that $H$. kuda consists of 2 major lineages that are associated with the Indian Ocean and the West Pacific, respectively. It is possible that these lineages represent cryptic, reproductively isolated species whose distributions overlap in Southeast Asia. Future research using nuclear markers such as microsatellites could determine whether introgression has taken place between these 2 lineages.

Acknowledgements. We thank S. Serebiah for providing us with samples from Tamil Nadu (India), and A.S. is thankful to the Director, National Institute of Oceanography (NIO), Goa (India) for facilities and encouragement. The manuscript was considerably improved by the comments of Nigel Barker and 4 anonymous reviewers. This study was funded by an ex gratia bursary from the Harry Crossley Foundation awarded to P.R.T., a Leverhulme Study Abroad Studentship, Commonwealth Scholarship and Hydro Québec Scholarship awarded to S.A.L., and a National Research Foundation grant awarded to C.A.M. (GUN 2053617).

\section{LITERATURE CITED}

Avise JC (1994) Molecular markers, natural history and evolution. Chapman \& Hall, New York

Bard E (2003) Indian Ocean sea surface temperature reconstruction. IGBP pages/World Data Center for Paleoclimatology, Data Distribution Series \#2003-027. NOAA/ NGDC Paleoclimatology Program, Boulder, CO

Barton NH, Charlesworth B (1984) Genetic revolutions, founder effects and speciation. Annu Rev Ecol Syst 15:133-164

Bowen BW, Bass AL, Rocha LA, Grant WS, Robertson DR (2001) Phylogeography of the trumpetfishes (Aulostomus): ring species complex on a global scale. Evolution 55: 1029-1039 
Carson HL (1975) The genetics of speciation at the diploid level. Am Natur 109:83-92

Castelloe J, Templeton AR (1994) Root probabilities for intraspecific gene trees under neutral coalescent theory. Mol Phylogenet Evol 3:102-113

Cavalcanti MJ (1988-2000) MANTEL-test for association between 2 symmetric distance matrices with permutation iterations. Setor de Paleovertebrados, Departamento de Geologia e Paleontologia, Museu Nacional do Rio de Janeiro, Quinta da Boa Vista, São Cristóvão, 20940-040, Rio de Janeiro

Clement M, Posada D, Crandall KA (2000) TCS: a computer program to estimate gene genealogies. Mol Ecol 9: $1657-1660$

Coyne JA (1994) Ernst Mayr and the origin of species. Evolution 48:19-30

Crandall KA, Templeton AR (1993) Empirical tests of some predictions from coalescent theory with applications to intraspecific phylogeny reconstruction. Genetics 134: 959-969

Dawson CE (1986) Family No. 145: Syngnathidae. Smith MM, Heemstra PC (eds) Smith's sea fishes. Macmillan South Africa, Johannesburg, p 445-458

Excoffier L, Smouse PE, Quattro JM (1992) Analysis of molecular variance inferred from metric distances among DNA haplotypes: application to human mitochondrial DNA restriction data. Genetics 131:479-491

Fleminger A (1986) The Pleistocene equatorial barrier between the Indian and Pacific oceans and a likely cause for Wallace's Line. In: Pierrot-Bults AC, van der Spoel S, Zahuranec BJ, Johnson RK (eds) Pelagic marine science. UNESCO Tech Pap Mar Sci 49:84-97

Godfrey JS (1996) The effect of the Indonesian throughflow on ocean circulation and heat exchange with the atmosphere: a review. J Geophys Res 101:12217-12238

Gooding R, Magnuson J (1967) Ecological significance of a drifting object to pelagic fishes. Pac Sci 21:486-497

Gore RH, Gallaher EE, Scotto LE, Wilson KA (1981) Studies on Decapod Crustacea from the Indian River region of Florida. XI. Community composition, structure, biomass and species-areal relationships of seagrass and drift algae-associated macrocrustaceans. Estuar Coast Shelf Sci 12:485-508

Goren M (1986) A suggested model for the recolonization process of the Red Sea at the post glacial period. In: Uyeno T, Arai R, Taniuchi T, Matsuura K (eds) Indo-Pacific fish biology: Proc second int conf Indo-Pacific fishes. Ichthyological society of Japan, Tokyo, p 648-654

Gosling EM (1994) Speciation and species concepts in the marine environment. In: Beaumont AR (ed) Genetics and evolution of aquatic organisms. Chapman \& Hall, London, p 1-14

Hasegawa M, Kishino K, Yano, T (1985) Dating the humanape splitting by a molecular clock of mitochondrial DNA. J Mol Evol 22:160-174

Helmuth B, Veit RR, Holberton R (1994) Long-distance dispersal of a subantarctic brooding bivalve (Gaimardia trapesina) by kelp-rafting. Mar Biol 120:421-426

Highsmith RC (1985) Floating and algal rafting as potential dispersal mechanisms in brooding invertebrates. Mar Ecol Prog Ser 25:169-179

Hobday AJ (2000) Persistence and transport of fauna on drifting kelp (Macrocystis pyrifera (L.) C. Agardh) rafts in the Southern California Bight. J Exp Mar Biol Ecol 253:75-96

Holmquist JG (1994) Benthic macroalgae as a dispersal mechanism for fauna: influence of a marine tumbleweed. J Exp Mar Biol Ecol 180:235-251
Hunt A (1993) Effects of contrasting patterns of larval dispersal on the genetic connectedness of local populations of 2 intertidal starfish, Patiriella calcar and Patiriella exigua. J Exp Mar Biol Ecol 92:179-186

Ingolfsson A (1995) Floating clumps of seaweed around Iceland: Natural microcosms and a means of dispersal for shore fauna. Mar Biol 122:13-21

Jackson DA, Somers, KM (1989) Are probabilities estimates from the permutation model of Mantel's test stable? Can J Zool 67:766-769

Jacobs RP, Dicks B (1985) Seagrass in the Zeit Bay area and the Ras Gharib (Egyptian Red Sea coast). Aquat Bot 23: $137-147$

Johannesson K (1988) The paradox of Rockall: why is a brooding gastropod (Littorina saxatilis) more widespread than one having a planktonic larval dispersal stage (L. littorea)? Mar Biol 99:507-513

Jokiel PL (1984) Long distance dispersal of reef corals by rafting. Coral Reefs 3:113-116

Knowlton N (1993) Sibling species in the sea. Annu Rev Ecol Syst 24:189-216

Kokita T, Omori M (1999) Long distance dispersal of larval and juvenile rockfish, Sebastes thompsoni, with drifting seaweed in the Tohoku area, north-west Pacific. Bull Mar Sci 65:105-118

Kuiter RH (2000) Seahorses, pipefishes and their relatives - a comprehensive guide to syngnathiformes. TMC Publishing, Chorleywood

Kulczycki GR, Virnstein RW, Nelson WG (1981) The relationship between fish abundance and algal biomass in a seagrass-drift algae community. Estuar Coast Shelf Sci 99: $215-220$

Lande R (1980) Genetic variation and phenotypic evolution during allopatric speciation. Am Natur 116:463-479

Lipkin Y (1977) Quantitative aspects of seagrass communities, particularly those dominated by Halophila stipulacea, in Sinai (northern Red Sea). Aquat Bot 7:119-128

Lourie SA (2004) Phylogeography of southeast Asian seahorses in a conservation context. PhD thesis, McGill University, Montreal

Lourie SA, Vincent ACJ, Hall HJ (1999) Seahorses: an identification guide to the world's species and their conservation. Project Seahorse, London

Madhupratap M, Nair KNV, Gopalkrishnan TC, Haridas P, Nair KKC, Venugopal P, Gauns M (2001) Arabian Sea oceanography and fisheries of the west coast of India. Curr Sci 81:355-361

Mantel N (1967) The detection of disease clustering and a generalised regression approach. Cancer Res 27:209-220

Maree RC, Whitfield AK, Booth AJ (2000) Effect of water temperature on the biogeography of South African estuarine fishes associated with the subtropical/warm temperate subtraction. S Afr J Sci 96:184-188

Martel A, Chia FS (1991) Drifting and dispersal of small bivalves and gastropods with direct development. J Exp Mar Biol Ecol 150:131-147

Mayr E (1954) Change of genetic environment and evolution. In: Huxley J, Hardy AC, Ford EB (eds) Evolution as a process. Allen \& Unwin, London, p 157-180

Mayr E (1963) Animal species and evolution. Harvard University Press, Cambridge, MA

Miller MA (1968) Isopoda and Tanaidacea from buoys in coastal waters of the continental United States, Hawaii and the Bahamas (Crustacea). Proc US Natl Mus 125:1-53

Mora C (2001) Dispersal of reef fishes by rafting. Reef Encount 29:16-17

Moritz C (1994) Defining 'Evolutionary significant units' for 
conservation. Trends Ecol Evol 9:373-375

Morton B, Britton JC (2000) The origins of the coastal and marine flora and fauna of the Azores. Mar Biol 38:13-84

Moya A, Galiana A, Ayala FJ (1995) Founder-effect speciation theory: failure of experimental corroboration. Proc Natl Acad Sci USA 92:3983-3986

Nielsen R, Wakeley J. (2001). Distinguishing migration from isolation: A markov chain monte carlo approach. Genetics 158:885-896

Palsbøll PJ, Bérubé M, Aguilar A, Notarbartolo-Di-Sciara G, Nielsen R (2004) Discerning between recurrent gene flow and recent divergence under a finite-site mutation model applied to North Atlantic and Mediterranean Sea fin whale (Balaenoptera physalus) populations. Evolution 58: 670-675

Parker T, Tunnicliffe V (1994) Dispersal strategies of the biota on an oceanic seamount: implications for ecology and biogeography. Biol Bull (Woods Hole) 187:336-345

Paulay G, Meyer C (2002) Diversification in the tropical Pacific: comparisons between marine and terrestrial systems and the importance of founder speciation. Integr Comp Biol 42:922-934

Perante NC, Pajaro MG, Vincent ACJ (1998) Demographics of the seahorse Hippocampus comes in the central Philippines. In: Morton B (ed) Proc 3rd Int Conf Marine Biology of the South China Sea. Hong Kong University Press, Hong Kong, p 439-448

Por DF (1978) Lessepsian migration. Springer-Verlag, Berlin

Posada D, Crandall KA (1998) MODELTEST: testing the model of DNA substitution. Bioinformatics 14:817-818

Rice WR, Hostert EE (1993) Laboratory experiments on speciation: what have we learned in 40 years? Evolution 47: $1637-1653$

Ringo J, Wood D, Rockwell R, Dowse H (1985) An experiment testing 2 hypotheses of speciation. Am Natur 126:642-661

Rodríguez F, Oliver JF, Marín A, Medina JR (1990) The general stochastic model of nucleotide substitution. J Theor Biol 142:485-501

Rogers AR, Harpending H (1992) Population growth makes waves in the distribution of pairwise genetic differences. Mol Biol Evol 9:552-569

Rozas J, Rozas R (1999) DnaSP version 3: an integrated program for molecular population genetics and molecular evolution analysis. Bioinformatics 15:174-168

Russo CAM, Sole-Cava AM, Thorpe JP (1994) Population structure and genetic variation in 2 tropical sea anemones (Cnidaria, Actinidae) with different reproductive strategies. Mar Biol 119:267-276

Safina C (1998) Song for the blue ocean: encounters along the world's coasts and beneath the seas. Henry Holt, New York

Saitou N, Nei M (1987) The neighbor-joining method: a new method for reconstructing phylogenetic trees. Mol Biol Evol 4:406-425

Scheltema RS (1971) Larval dispersal as a means of genetic exchange between geographically separated populations of shallow-water benthic invertebrates. Biol Bull (Woods Hole) 140:284-322

Scheltema RS (1978) On the relationship between dispersal of pelagic veliger larvae and the evolution of marine prosobranch gastropods. In: Battaglia B, Beardmore JA (eds) Marine organisms: genetics, ecology and evolution. Plenum Press, New York, p 302-322

Schneider S, Roessli D, Excoffier L (2000) ARLEQUIN version 2.000: A software for population genetics data analysis. Genetics and biometry laboratory, University of Geneva, Geneva
Shetye SR, Shenoi SSC, Gouveia AD, Michael GS, Sundar D, Nampoothiri G (1991) Wind-driven coastal upwelling along the western boundary of the Bay of Bengal during the Southwest Monsoon. Cont Shelf Res 11:1397-1408

Slatkin M, Hudson RR (1991) Pairwise comparisons of mitochondrial DNA sequences in stable and exponentially growing populations. Genetics 129:555-562

Sponer R, Roy MS (2002) Phylogeographic analysis of the brooding brittle star Amphipholis squamata (Echinodermata) along the coast of New Zealand reveals high cryptic genetic variation and cryptic dispersal potential. Evolution 56:1954-1967

Stoddart JA (1984) Genetic differentiation amongst populations of the coral Pocillopora damicornis off southwestern Australia. Coral Reefs 3:149-156

Swofford DL (2002) PAUP* - phylogenetic analysis using parsimony ( ${ }^{*}$ and other methods), Version $4.0 \mathrm{~b} 10$. Sinauer Associates, Sunderland, MA

Tamura K, Nei M (1993) Estimation of the number of nucleotide substitutions in the control region of mitochondrial DNA in humans and chimpanzees. Mol Biol Evol 10: 512-526

Templeton AR (1980) The theory of speciation via the founder principle. Genetics 94:1011-1038

Templeton AR (1981) Mechanisms of speciation - a population genetics approach. Annu Rev Ecol Syst 12:23-48

Templeton AR (1999) Experimental tests of genetic transilience. Evolution 53:1628-1632

Templeton AR, Crandall KA, Sing CF (1992) A cladistic analysis of phenotypic associations with haplotypes inferred from restriction endonuclease mapping and DNA sequence data. III. Cladogram estimation. Genetics 132: 619-633

Teske PR (2003) Population genetics and phylogenetic placement of the endangered Knysna seahorse, Hippocampus capensis. PhD thesis, Stellenbosch University, Stellenbosch

Teske PR, Cherry MI, Matthee CA (2003) Population genetics of the endangered Knysna seahorse, Hippocampus capensis. Mol Ecol 12:1703-1716

Teske PR, Cherry MI, Matthee CA (2004) The evolutionary history of seahorses (Syngnathidae: Hippocampus): molecular data suggest a West Pacific origin and 2 invasions of the Atlantic Ocean. Mol Phylogenet Evol 30:273-286

Thompson JD, Gibson TJ, Plewniak F, Jeanmougin F, Higgins DG (1997) The ClustalX windows interface: flexible strategies for multiple sequence alignment aided by quality analysis tools. Nucleic Acids Res 24:4876-4882

Tomczak M, Godfrey JS (2003) Regional oceanography: an introduction, 2nd edn. Daya Publishing House, Delhi

Virnstein RW, Howard RK (1987) Motile epifauna of marine macrophytes in the Indian River Lagoon, Florida. II. Comparisons between drift algae and three species of seagrasses. Bull Mar Sci 41:13-26

Waters JM, Roy MS (2004) Out of Africa: the slow train to Australasia. Syst Biol 53:18-24

Worcester SE (1994) Adult rafting versus larval swimming: dispersal and recruitment of a botryllid ascidian on eelgrass. Mar Biol 121:309-317

Wright S (1931) Evolution in mendelian populations. Genetics 16:97-159

Wyrtki K (1961) Physical oceanography of the southeast Asian waters. Scientific results of maritime investigations of the South China Sea and the Gulf of Thailand 1959-1961. Naga Report, 2. Scripps Institution of Oceanography, La Jolla, CA

Submitted: July 15, 2004; Accepted: October 12, 2004

Proofs received from author(s): January 24, 2005 